\title{
BMJ Open To what extent are GCS and AVPU equivalent to each other when assessing the level of consciousness of children with head injury? A cross-sectional study of UK hospital admissions.
}

\author{
Amy GL Nuttall, Katie M Paton, Alison M Kemp
}

To cite: Nuttall AGL, Paton KM, Kemp AM. To what extent are GCS and AVPU equivalent to each other when assessing the level of consciousness of children with head injury? A cross-sectional study of UK hospital admissions.. BMJ Open 2018;8:e023216. doi:10.1136/ bmjopen-2018-023216

- Prepublication history and additional material for this paper are available online. To view these files, please visit the journal online (http://dx.doi org/10.1136/bmjopen-2018023216).

Received 28 March 2018 Revised 9 July 2018 Accepted 19 September 2018

Check for updates

(C) Author(s) (or their employer(s)) 2018. Re-use permitted under CC BY-NC. No commercial re-use. See rights and permissions. Published by BMJ.

Division of Population Medicine, Cardiff University, Cardiff, UK

Correspondence to

Dr Alison M Kemp;

KempAM@cardiff.ac.uk

\section{ABSTRACT}

Objective To evaluate utility and equivalence of Glasgow Coma Scale (GCS) and the Alert, Voice, Pain, Unresponsive (AVPU) scale in children with head injury.

Design Cross sectional study.

Setting UK hospital admissions: September 2009_

February 2010.

Patients $<15$ years with head injury.

Interventions GCS and/or AVPU at injury scene and in emergency departments (ED).

Main outcome Measures used, the equivalence of AVPU to GCS, GCS at the scene predicting GCS in ED, CT results by age, hospital type.

Results Level of consciousness was recorded in $91 \%$ (5168/5700) in ED (43\%: GCS/30.5\%: GCS+AVPU/17.3\%: AVPU) and $66.1 \%(1190 / 1801)$ prehospital (33\%:

GCS/26\%GCS+AVPU/7\%: AVPU). Failure to record level of consciousness and the use of AVPU were greatest for infants. Correlation between AVPU and median GCS in 1147 children $<5$ years: $A=15, V=14, P=8, U=3$, for 1163 children $\geq 5$ years: $A=15, V=13, P=11, U=3$. There was no significant difference in the proportion of infants who had a CT whether AVPU=V/P/U or GCS $<15$. However diagnostic yield of intracranial injury or depressed fracture was significantly greater for V/P/U than GCS $<15: 7 / 7: 100 \%$ (95\% Cl 64.6\% to $100 \%$ ) versus 5/17: $29.4 \%$ (95\% Cl $13.3 \%$ to $53.1 \%$ ). For children $>1$ year significantly more had a CT scan when GCS $<14$ was recorded than 'V/P/U only' and the diagnostic yield was greater. Prehospital GCS and GCS in the ED were the same for $77.4 \%$ (705/911). Conclusion There was a clear correlation between Alert and $\mathrm{GCS}=15$ and between Unresponsive and $\mathrm{GCS}=3$ but a wider range of GCS scores for responsive to Pain or Voice that varied with age. AVPU was valuable at initial assessment of infants and did not adversely affect the proportion of infants who had head CT or the diagnostic yield.

\section{INTRODUCTION}

An estimated 30000 children are admitted to hospitals in England annually with head injury. ${ }^{1}$ Although the majority of injuries are mild with a low mortality rate $(<0.5 \%)$,
Strengths and limitations of this study

- This is the largest study to explore the equivalence of AVPU to Glasgow Coma Scale (GCS) in children admitted to hospital with head injury.

- It is the only study to date to compare the outcomes for AVPU and GCS in children with head injury.

- The retrospective, multicentre design may limit findings due to impaired completeness and variation in data quality.

- Study numbers are limited by the lower numbers of children with severe loss of consciousness, however this represents real world epidemiology.

an estimated $15 \%-20 \%$ have moderate to severe traumatic brain injury. ${ }^{2}$ Children with impaired levels of consciousness have the greatest risk of significant morbidity or mortality. ${ }^{23}$ Clinicians rely on scores, such as the Glasgow Coma Scale (GCS) to evaluate levels of consciousness to identify children who need further investigation and early intervention. ${ }^{4}$

Teasdale and Jennet devised the GCS in 1974 (modified in 1976) ${ }^{45}$ (online supplementary table 1). It scores levels of neurological dysfunction in three components; motor, verbal and eye opening responses that are considered separately and combined into an overall score. Evaluating levels of consciousness in young children is challenging due to their limited verbal and motor responses, and several adaptations to the GCS for $<5$ years olds have been proposed. ${ }^{6}$ UK head injury guidelines recommend the paediatric GCS (pGCS) for infants $<1$ year old. ${ }^{37}$

National Institute for Health and Care Excellence (NICE) guidelines from 2003 to 2014 recommend that all children with a head injury have a GCS recorded at prehospital assessment and when seen in emergency 
departments (ED), that infants have a CT scan when GCS is $<15$ and for the older children CT is recommended when GCS $<14^{3}$ Ambulance staff, ED and child health clinicians receive regular updated training in its application. The score provides a baseline to facilitate triage, monitor levels of consciousness and aid decisions about whether CT imaging is required, the level of care and need for specialist involvement. However, studies have identified high levels of inter-rater variability, and variability in outcome prediction based on GCS. ${ }^{89}$

The complexity of the GCS compared with other simpler scores raises concerns about its utility ${ }^{10}$ and alternative shorter scores are used. The AVPU score (online supplementary table 1) was introduced by the American College of Surgeons ${ }^{11}$ to monitor the patients with poisoning. ${ }^{12}$ It is less detailed and has four broad scores, A, Alert; V, responsive to Verbal stimulus; P, responsive to Painful stimulus; U, Unresponsive. No formal training is required to administer this score and it can be used easily at the site of injury. ${ }^{13}$

The Confidential Enquiry into Head Injury in Childhood was the principal project within the Centre for Maternal and Child Enquires (CMACE) collected data from hospital admissions for head injury across the UK. This large dataset provided the opportunity to evaluate the clinical practice of recording levels of consciousness for children with head injury.

This study aims to describe the utilisation of GCS and AVPU in children with head injury, to determine the correlation between AVPU and GCS scores for children older and those younger than 5 years of age and to explore whether the scoring system that is used to measure of level of consciousness affects the rate of CT scan and subsequent diagnostic yield.

\section{METHODS}

Data were collected from the case notes of children up to 15 years of age admitted to hospital for more than 4 hours following a head injury between September 2009 and February 2010. Ninety per cent of hospitals that admit children for head injury in England, Wales, Northern Ireland and the Channel islands participated in the study. ${ }^{14}$ Children with superficial or facial injuries that were unlikely to be associated with brain injury were excluded. The data collection proformas were designed to follow the child's pathway of care and to obtain information that was available from the child's hospital records. Proformas (online supplementary figure $1 \mathrm{a}, \mathrm{b}$ ) were completed by local head injury enquiry coordinators (previously identified in each hospital) and entered onto a secure CMACE database and placed in SPSS Statistics V.19 for analysis.

Data were collected for each child for GCS total and component scores, AVPU score, age, the type of hospital to which the child was admitted (specialist hospitals were defined as designated children's hospital, or those that became major trauma centres in 2012 and general hospitals, were those that had none of these facilities), whether or not the children received a CT scan and the diagnostic yield of intracranial abnormality or depressed fracture.

\section{Analysis}

We describe the proportion of children $<15$ years who had their level of consciousness recorded using GCS or AVPU respectively in the prehospital setting and at the first clinical assessment at ED. We have calculated the median and IQR of GCS scores for each aspect of AVPU to determine the correlation between GCS and AVPU for children $<5$ years old and those $>5$ where both scores were applied.

We compared the proportion of CT scans undertaken and the CT findings, between children who had their level of consciousness measured using AVPU, those measured with GCS and those where both scores were recorded to determine whether there was any difference according to the method used to record level of consciousness. This was undertaken for children $<1$ year and those $>1$ year as NICE guidelines lines for when a head CT scan should be undertaken vary for these two age groups ${ }^{3}$ : for infants, a CT scan is recommended in those where GCS $<15$, where AVPU only was recorded we extrapolated that this should be equivalent of a $\mathrm{V} / \mathrm{P} / \mathrm{U}$. For older children the recommendation is for a CT scan if GCS $<14$, again we chose a cut-off of $\mathrm{V} / \mathrm{P} / \mathrm{U}$ when GCS was not recorded.

We described the association between prehospital GCS and GCS in the ED to determine the extent of change between ambulance recorded GCS and that on admission. All analyses were undertaken using the online tool Vassar Stats ${ }^{15}$ to calculate $95 \%$ CIs of proportion based on continuity-corrected versions of the Wilson interval. Fisher's exact test was used to calculate levels of significance at $\mathrm{p}<0.05$.

\section{Patient and public involvement}

This was an analysis undertaken from data collected for the National Child Health Outcome review on head injuries, based on a National Health Service priority. Both patients and professionals were consulted during design of the study proformas. Patient recruitment was via anonymised case note review, with ethical and CAG approvals. The overall study findings have been disseminated in a publicly available report.

\section{RESULTS}

Overall, 5700 children were included in the study, median age 49 months, $61.4 \%$ (3500) were boys (online supplementary figure 2), 1801 children were transported to hospital by ambulance and 385 were transferred on to a second hospital (data were available for 318 of these latter cases).

Overall $90.6 \%(5168 / 5700)$ of children had their consciousness level recorded in the ED at the first hospital to which they were admitted, as did $85 \%(271 / 318)$ of children who were transferred to a second hospital, $66.1 \%$ $(1190 / 1801)$ of the children transported to hospital by 
Table 1 The proportion of children $(n=5700)$ who had GCS or AVPU recorded in prehospital setting and on admission to subsequent hospitals.

\begin{tabular}{|c|c|c|c|c|c|}
\hline & GCS only \% (95\% Cl) (n) & GCS and AVPU $\%$ (n) & AVPU only \% (n) & Not recorded \% (n) & Total \\
\hline \multirow{2}{*}{$\begin{array}{l}\text { Prehospital } \\
\text { assessment }\end{array}$} & $33.0 \%$ & $25.9 \%$ & $7.2 \%$ & $33.9 \%$ & 1801 \\
\hline & $(594)$ & $(467)$ & (129) & $(611)$ & \\
\hline $\begin{array}{l}\text { Hospital assessment } \\
\text { in ED }\end{array}$ & $(2443)$ & (1739) & $(986)$ & (532) & \\
\hline $\begin{array}{l}\text { Second hospital } \\
\text { assessment on } \\
\text { admission }\end{array}$ & $47.2 \%$ & $29.6 \%$ & $8.5 \%$ & $14.8 \%$ & 318 \\
\hline Total & $3187(40.7 \%)$ & $2300(29.4 \%)$ & $1142(14.6 \%)$ & $1190(15.2 \%)$ & 7819 \\
\hline
\end{tabular}

ED, emergency departments; GCS, Glasgow Coma Scale.

ambulance had their consciousness level recorded at the scene of the incident (table 1).

The proportion of children who had an 'AVPU only' or no recording was higher for younger children and decreased with age, whereas the proportion of children who had a 'GCS only' increased with the age (figure 1). Overall $73.5 \%$ (4426/6018) of child hospital attendances had a GCS recorded. Of the total 5487 GCS recorded only $75.4 \%$ (4137) had the component scores documented.

Children were first taken to a general hospital in $83.6 \%$ (4768) of cases, and specialist hospitals in the remainder. The specialist hospitals recorded an APVU in significantly fewer cases than the general hospitals (13.6\%: 95\% CI 11.6\% to $16.0 \%$ vs $18 \%$ : $95 \%$ CI $16.9 \%$ to $19.1 \%$ ) (figure 1 ).

\section{Correlation between AVPU and GCS}

In the complete dataset 2300 children had both AVPU and GCS recorded at the same point of care. Of these AVPU scores, $91.4 \%(2102)=\mathrm{A}, 4 \%(92)=\mathrm{V}, 2 \%(47)=\mathrm{P}$ and $2.6 \%$ $(59)=\mathrm{U}$. The correlation between AVPU and GCS differed between the 1137 children $<5$ years and those $\geq 5$ years old $(\mathrm{n}=1163)$. For children $<5$ years, the median scores and IQRs were $\mathrm{A}=15$ (IQR 0), $\mathrm{V}=14$ (IQR 13-15), $\mathrm{P}=8$ (IQR 6-9) and $U=3$ (IQR 3-6) (online supplementary figure 3a). There was no significant difference within this age band between those younger and those $>1$ year of age. For children of $\geq 5$ years, the median scores were $A=15$ (IQR 0 ), $\mathrm{V}=13$ (IQR 12-14), $\mathrm{P}=11$ (8 to 12) and $\mathrm{U}=3$ (IQR 3-5) (online supplementary figure $3 \mathrm{~b}$ ).

\section{For children $<1$ year and those $>1$ year, was there any} difference between the proportion of CT scans performed and the diagnostic yield according to the method of recording the level of consciousness?

Table 2 shows that there was no statistically significant difference between the proportion of CT scans undertaken in the three groups of infants, (i) with a GCS $<15$, (ii) where the AVPU score was $\mathrm{V} / \mathrm{P} / \mathrm{U}$ or (iii) those with a recorded $\mathrm{AVPU}=\mathrm{V} / \mathrm{P} / \mathrm{U}$ and a $\mathrm{GCS}<15$. While numbers were small, significantly more infants with $\mathrm{AVPU}=\mathrm{V} / \mathrm{P} / \mathrm{U}$ or $\mathrm{V} / \mathrm{P} / \mathrm{U}$ and $\mathrm{GCS}<15$ had intracranial injury (ICI) or depressed fracture on CT than those who had a GCS $<15$ $(\mathrm{p}<0.01)$. When infants were Alert and/or GCS was 15,
$10.2 \%-23.8 \%$ of children who had a CT scan had an abnormality identified.

For the older children, a significantly greater proportion of children had a CT when the GCS was $<14$, or the AVPU was $\mathrm{V} / \mathrm{P} / \mathrm{U}$ and $\mathrm{GCS}<14$ than when the AVPU only was recorded as $\mathrm{V} / \mathrm{P} / \mathrm{U}(\mathrm{p}<0.001)$. The diagnostic yield was significantly greater in these two groups than when AVPU only was recorded (table 2). For children who were Alert and/or who had a GCS $=14 / 15,7.6 \%-12.4 \%$ who had a CT scan had an abnormality.

When both AVPU and GCS were recorded and there was an apparent discrepancy between the scores (ie, Alert with a GCS $<15$ or GCS of 15 and AVPU $=\mathrm{V} / \mathrm{P} / \mathrm{U}$ ), it was not possible to determine what influenced the decision to undertake a CT scan.

\section{To what extent does GCS recorded at the scene of injury} reflect the GCS on admission?

The GCS at the scene had a positive predictive value (PPV) of $77.4 \%$ (705/911) for the same GCS in the ED. The PPV for a GCS of 15 on hospital admission for children with a prehospital GCS of 15 was $88.6 \%$. Thus $11.3 \%$ (73) of children with a GCS of 15 at the scene had deteriorated by the time their GCS was recorded in ED. All 13 children who died had a GCS of $\leq 8$ at the scene. GCSs $\leq 14$ had a PPV of $71 \%$ $(191 / 269)$ for $\mathrm{GCSs} \leq 14$ on admission (table 3$)$.

\section{DISCUSSION}

The consciousness level was documented in $90 \%$ of children admitted to hospital with head injury. Overall the majority of hospital and prehospital admissions had a GCS recorded. While this is in keeping with current NICE guidelines, ${ }^{3}$ it was not universal practice and $30 \%$ of assessments reported in this study used either AVPU only or had no measure of conscious state recorded. The AVPU was most frequently used for infants $<1$ year old, while the GCS was used more frequently in older children. This finding is likely to be due to difficulties applying the GCS in infancy, despite the pGCS that is designed to account for these limitations. 

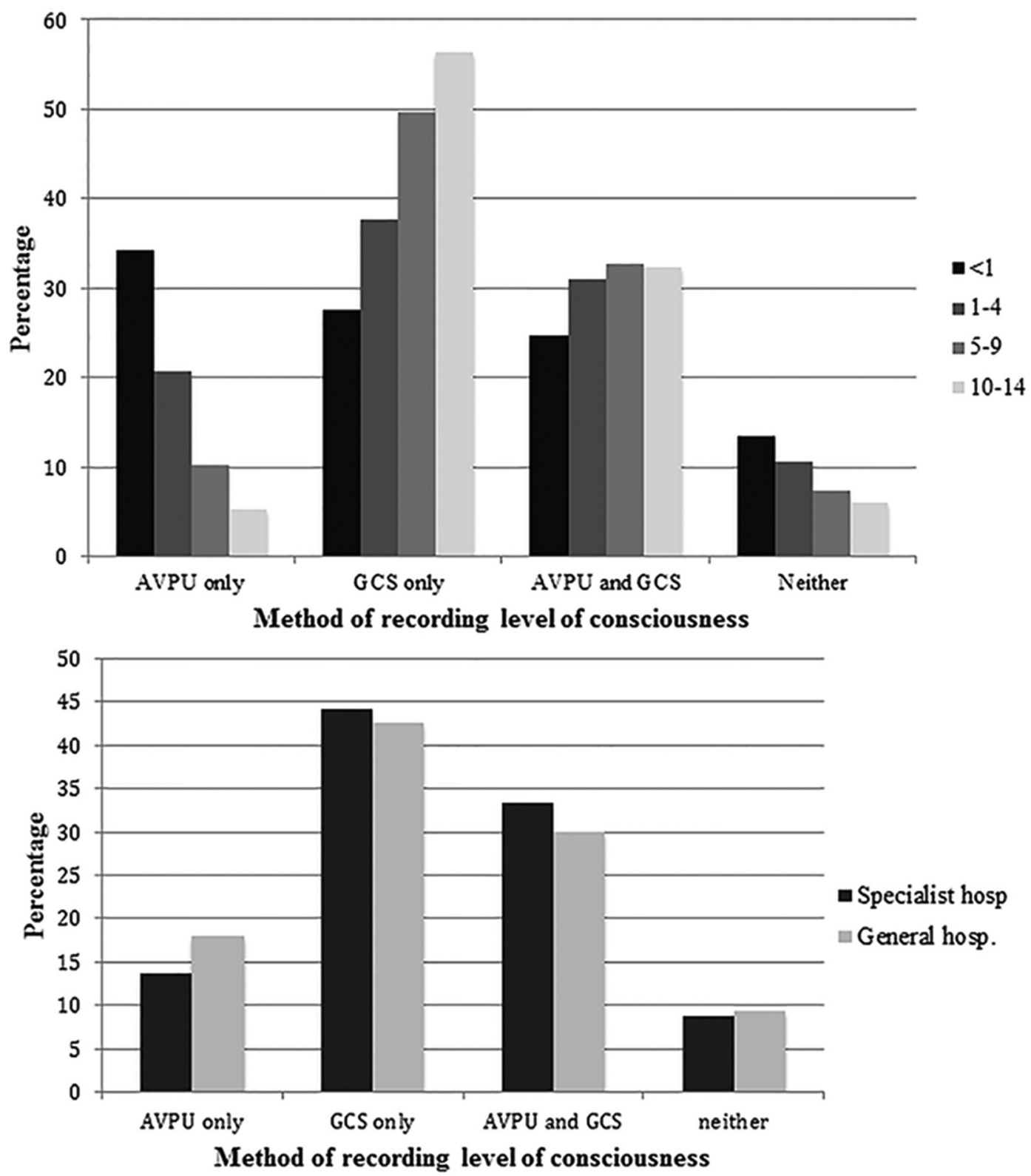

Figure 1 Proportion of children who had level of consciousness recorded and methods used in first hospital attended, by age group (<1, 1-4, 5-9, 10-14 years) and by specialist or general hospitals. (AVPU only: $n=986$; GCS only: $n=2443$; GCS and AVPU: $n=1739$; no recording: $n=532$, eight children excluded as age was not recorded.) GCS, Glasgow Coma Scale; hosp., hospital.

The use of the 'AVPU only' in infancy ( $<1$ year) did not adversely affect the clinical management or diagnosis in terms of the proportion of children who had CT head scans undertaken and the diagnostic yield. Indeed, it could be argued that the AVPU $=\mathrm{V} / \mathrm{P} / \mathrm{U}$ was a more specific measure of serious head injury in this age group, as a significantly greater proportion of the children with a recorded $\mathrm{AVPU}=\mathrm{V} / \mathrm{P} / \mathrm{U}$ had an ICI or a depressed fracture on CT scan when compared with cases where 'GCS only' was applied. However, among older children the GCS was a better predictor of an abnormal CT as in those with a GCS $<14$, significantly more children had a CT scan and significantly more of these scans were abnormal than when $\mathrm{V} / \mathrm{P} / \mathrm{U}$ only was recorded. The level of consciousness is not the only factor to influence the decision to undertake a CT scan. ${ }^{3}$ This study confirms that an estimated 1 in 5-10 children with no impaired consciousness had an abnormality on CT. Influential factors for the same series of children are described further in Kemp et $a l .{ }^{16}$ However, these results would support the inclusion of AVPU as an acceptable initial measure of level of consciousness in infants and support a recommendation that a CT scan should be undertaken if $A V P U=V / P / U$.

The AVPU is simple, but none of the components are clearly defined. When considering the theoretical equivalence of AVPU to the components of the GCS, there is a range of total GCS that could be equivalent to each AVPU component. The definitions of eye opening scores (E1-4) can be directly related to the AVPU responses. However, an Alert child could be equivalent to a GCS of 15 or 14 as 
Table 2 The number and proportion of children who had a CT scan when either an 'AVPU only' $(n=986)$ 'GCS only' $(n=2443)$ or both scores $(n=1739)$ were recorded in $E D$ and number and proportion of $\mathrm{ICl}$ or depressed fractures in those who had head CT

\begin{tabular}{|c|c|c|c|c|c|}
\hline & & Children (n) & $\begin{array}{l}\text { No } \% \text { who had CT with } \\
95 \% \mathrm{Cl}\end{array}$ & Unknown & $\begin{array}{l}\text { No } \%(95 \% \mathrm{Cl}) \text { of those } \\
\text { who had } \mathrm{CT} \text { with ICI or } \\
\text { depressed fracture }\end{array}$ \\
\hline \multicolumn{6}{|l|}{$<1$ year of age } \\
\hline \multirow[t]{2}{*}{$\begin{array}{l}\text { AVPU } \\
n=375\end{array}$} & Alert & 358 & $\begin{array}{l}63 \\
17.6 \% \text { (14\% to } 21.9 \%)\end{array}$ & 3 & $\begin{array}{l}15 / 63 \\
23.8 \% \text { (15\% to } 35.6 \%)\end{array}$ \\
\hline & $\mathrm{V} / \mathrm{P} / \mathrm{U}$ & 17 & $\begin{array}{l}7 \\
41.2 \%(21.6 \% \text { to } 64 \%)\end{array}$ & 0 & $\begin{array}{l}7 / 7 \\
100 \%(64.6 \% \text { to } 100 \%)\end{array}$ \\
\hline \multirow[t]{2}{*}{$\begin{array}{l}\text { GCS } \\
n=301\end{array}$} & 15 & 269 & $\begin{array}{l}59 \\
21.9 \%(17.4 \% \text { to } 27.3 \%)\end{array}$ & 5 & $\begin{array}{l}13 / 59 \\
22 \%(13.4 \% \text { to } 34 \%)\end{array}$ \\
\hline & $<15$ & 32 & $\begin{array}{l}17 \\
53.1 \% \text { (36.5\% to } 69.1 \%)\end{array}$ & 0 & $\begin{array}{l}5 / 17 \\
29.4(13.3 \% \text { to } 53.1 \%)\end{array}$ \\
\hline \multirow{3}{*}{$\begin{array}{l}\text { AVPU and } \\
\text { GCS } \\
n=270\end{array}$} & Alert/GCS=15 & 247 & $\begin{array}{l}59 \\
23.9 \% \text { (19.0\% to } 29.6 \%)\end{array}$ & 1 & $\begin{array}{l}6 / 59 \\
10.2 \% \text { (4.8\% to } 20.5 \%)\end{array}$ \\
\hline & $\begin{array}{l}\text { Discrepant scores } \\
\text { Alert/GCS }<15(n=14) \\
\text { or GCS } 15 \text { and VIP/U } \\
(n=2)\end{array}$ & 16 & $\begin{array}{l}5 \\
31.3 \%(14.2 \% \text { to } 55.6 \%)\end{array}$ & & $\begin{array}{l}2 / 5 \\
40 \%(11.8 \% \text { to } 76.9 \%)\end{array}$ \\
\hline & V/P/U: GCS $<15$ & 7 & $\begin{array}{l}5 \\
71.4 \% \text { (36.0\% to } 92.0 \%)\end{array}$ & & $\begin{array}{l}5 / 5 \\
100 \%(56.6 \% \text { to } 100 \%)\end{array}$ \\
\hline \multicolumn{6}{|l|}{$>1$ year } \\
\hline \multirow[t]{2}{*}{$\begin{array}{l}\text { AVPU } \\
\mathrm{n}=610\end{array}$} & Alert & 581 & $\begin{array}{l}108 \\
18.6 \% \text { (15.6\% to } 21.9 \%)\end{array}$ & 5 & $\begin{array}{l}10 / 108 \\
9.3 \%(5.1 \% \text { to } 16.2 \%)\end{array}$ \\
\hline & $\mathrm{V} / \mathrm{P} / \mathrm{U}$ & 29 & $\begin{array}{l}13 \\
44.8 \%(28.4 \% \text { to } 64.5 \%)\end{array}$ & 0 & $\begin{array}{l}0 / 13 \\
0 \% \text { (0\% to } 22.8 \%)\end{array}$ \\
\hline \multirow[t]{2}{*}{$\begin{array}{l}\text { GCS } \\
n=2138\end{array}$} & $14-15$ & 1964 & $\begin{array}{l}630 \\
32 \% \text { (30\% to } 34.2 \%)\end{array}$ & 29 & $\begin{array}{l}78 / 630 \\
12.4 \% \text { (10\% to } 15.2 \%)\end{array}$ \\
\hline & $<14$ & 174 & $\begin{array}{l}145 \\
83.3 \%(77.1 \% \text { to } 88.1 \%)\end{array}$ & 1 & $\begin{array}{l}44 / 145 \\
30.3 \% \text { (23.4\% to } 38.3 \%)\end{array}$ \\
\hline \multirow{3}{*}{$\begin{array}{l}\text { AVPU and } \\
\text { GCS } \\
n=1466\end{array}$} & Alert/GCS=14 or 15 & 1338 & $\begin{array}{l}406 \\
30.7 \% \text { (28.3\% to } 33.2 \%)\end{array}$ & 15 & $\begin{array}{l}31 / 406 \\
7.6 \%(5.4 \% \text { to } 10.6 \%)\end{array}$ \\
\hline & $\begin{array}{l}\text { Discrepant scores } \\
\text { Alert/GCS }<14(n=27) \\
\text { or GCS } 14 \text { or } 15 / \text { and } V / P / U \\
(n=39)\end{array}$ & 66 & $\begin{array}{l}42 \\
63.6 \%(51.6 \% \text { to } 74.2 \%)\end{array}$ & 0 & $\begin{array}{l}3 / 42 \\
7.1 \% \text { (2.5\% to } 19.0 \%)\end{array}$ \\
\hline & V/P/U: GCS $<14$ & 62 & $\begin{array}{l}45 \\
72.6 \%(60.4 \% \text { to } 82.1 \%)\end{array}$ & 0 & $\begin{array}{l}18 / 45 \\
40 \% \text { (27\% to } 54.6 \%)\end{array}$ \\
\hline
\end{tabular}

Italics highlight the results were there was discrepancy between GCS and AVPU scores.

${ }^{*}$ Eight children excluded as age was unknown (one from AVPU group and four from GCS group, three from group with both scores).

ED, emergency departments; GCS, Glasgow Coma Scale; ICI, intracranial injury; P, responsive to painful stimulus; U, unresponsive; V, responsive to verbal stimulus.

they may be Alert but confused and have a verbal score of V4, however a verbal response would only be detectable in $>5$ year where the unmodified GCS is advised. An Unresponsive child should score an E1 and V1, however the motor response may include M3 as they may be decorticate or decerebrate. Therefore, the theoretical range for U could be a GCS 3-5.

It is less easy to align Verbal or Pain responsive categories of AVPU to GCS component scores due in part to the difference in pGCS and adult GCS. While the GCS component descriptors for the $<5$ year olds are more specific than for the older age group in terms of responsiveness there is still considerable scope for matching against different scores. For example, a child $<5$ years who responds to pain may score E2 for eye opening, V2-V3 for a verbal score and M2-5 for motor, that is, a total score between 6 and 10 while for a child $>5$ years the corresponding scores could be E2, V2-V5, M2-M5 totalling a score between 6 and 12. These wide ranges are reflected in the study results. Due to the large variability of $\mathrm{V} / \mathrm{P}$ on 
Table 3 GCS at the scene and in the ED for 911 children where both were recorded

\begin{tabular}{lrrrrr}
\hline GCS ED & $\mathbf{5}$ & $\mathbf{9 - 1 2}$ & $\mathbf{1 3 - 1 4}$ & $\mathbf{1 5}$ & $\begin{array}{l}\text { Total GCS } \\
\text { at scene }\end{array}$ \\
\hline $\begin{array}{l}\text { GCS scene } \\
\quad 15\end{array}$ & 4 & 5 & 64 & 570 & 643 \\
$13-14$ & 4 & 13 & 81 & 56 & 154 \\
$9-12$ & 8 & 16 & 11 & 8 & 43 \\
$\leq 8$ or died & 38 & 12 & 7 & 14 & 71 \\
$\begin{array}{l}\text { Total GCS } \\
\text { in ED }\end{array}$ & 54 & 46 & 163 & 648 & 911 \\
\hline
\end{tabular}

Shaded values, highlight where the GCS was the same in at the scene and in ED.

ED, emergency departments; GCS, Glasgow Coma Scale.

the GCS, the AVPU is not sufficiently precise to closely monitor neurological deterioration.

Table 4 lists published studies that compare GCS with AVPU scores. The majority support a clear correlation between Alert and GCS=15 and Unresponsive with GCS=3 with a wider range of associated GCS scores for responsive to Pain or Voice. There are only two smaller paediatric studies. ${ }^{1718}$ The most recent of which evaluated the use of AVPU in the prehospital setting to identify children who might require intubation or intensive care and concluded that an AVPU of A or V identified $100 \%$ of children with a pGCS of or exceeding eight, and therefore, at low risk of requiring intubation or intensive care treatment. ${ }^{18}$
GCS is a composite scoring system of three components which share no relationship and there are many clinically plausible score combinations. ${ }^{19}$ It is important to remember that the total GCS cannot be seen as a static and exact scale like the simpler scores and it should be used to measure change in each of its components with the total score to track the progress and consciousness of a patient. This emphasises the need for correct practice using the score, stating the component scores alongside total GCS on every communication and documentation as recommended by NICE. In this study only $75.4 \%$ of GCS scores had the component scores listed. This, however, does not take away the validity of using the total score as a guideline for the clinical management, that is, when a CT scan is recommended or appropriate airway intervention and the involvement of an anaesthetist. ${ }^{3}$

Prehospital GCS is a reasonable indicator of GCS in EDs and may be helpful in determining which children are at risk of serious head injury and require direct transfer to major trauma facilities, either in isolation or as part of a composite tool to be used in such situations.

However, for one in four children the GCS will change by the time they reach ED and ongoing monitoring with GCS in the prehospital period including all component scores is essential.

This study is the largest one to explore the equivalence of AVPU to GCS in children admitted to hospital with head injury, and the only one that attempts to compare the outcome for the two scoring systems in terms of investigations and diagnostic yield of serious cranial and ICI. The findings

Table 4 Previously published studies and equivalence of GCS and AVPU

\begin{tabular}{|c|c|c|c|c|c|}
\hline & & $A$ & $\mathbf{v}$ & $\mathbf{P}$ & $\mathbf{U}$ \\
\hline $\begin{array}{l}\text { Mackay }{ }^{13} \mathrm{n}=174,730 \\
\text { Ambulance transfers to emergency } \\
\text { departments } \\
\text { Age }>5 \text { years }\end{array}$ & $\begin{array}{l}\text { Most common } \\
\text { score (range) }\end{array}$ & $15(9-15)$ & $12(5-14)$ & $8(4-13)$ & $3(3-7)$ \\
\hline $\begin{array}{l}\text { McNarry }^{20} n=1000 \\
\text { Neurosurgical patients } \\
\text { All ages }\end{array}$ & Median score & 15 & 13 & 8 & 6 \\
\hline $\begin{array}{l}\text { Raman }^{17} \\
\mathrm{n}=159 \\
\text { Paediatric patients admitted to } \\
\text { paediatric intensive care unit } \\
\text { Age } 2 \text { months-12 years }\end{array}$ & Median (IQR) & $14(12-15)$ & $11(10-12)$ & $6(5.5-8)$ & $3(3-4)$ \\
\hline $\begin{array}{l}\text { Hoffman }^{18} \\
\mathrm{n}=302 \\
\text { Children prehospital emergencies } \\
\text { multiple diagnoses } \\
\text { Age }<10 \text { years }\end{array}$ & Median (IQR) & 15 (15) & $12(10-13)$ & $8.5(6-10)$ & $3(3)$ \\
\hline $\begin{array}{l}\text { Nuttall (2018) } \\
\mathrm{n}=5700 \\
\text { Age 5-15years }\end{array}$ & Median (IQR) & 15 (15) & $13(12-14)$ & $11(8-12)$ & $3(3-5)$ \\
\hline
\end{tabular}


are limited by its retrospective and multicentre design that may have impaired data completeness and variation in data quality between centres. Data were extracted from hospital case notes and while there may have been administrative errors that explained outlying results, clinical governance should ensure a level of accuracy within the case notes. We were unable to follow-up children who did not have CT and identify potentially missed cases of ICI or depressed fracture. While it was stated that measures were taken at the same point in the care pathway, we cannot be sure that temporal differences did not have an effect. Study numbers in this field will always be limited by the lower numbers of children with severe loss of consciousness, however this represents the real-world epidemiology of head injury where the majority of cases seen are minor head injuries.

\section{CONCLUSION}

Despite the current NICE guidelines, 25\% children with head injury did not have a GCS recorded in the ED rising to $40 \%$ of prehospital cases. This study found that the equivalence of AVPU to GCS varied between children $<5$ years and $>5$ years. The use of AVPU alone at the initial hospital assessment in infancy did not adversely affect the rate of initial neuroradiological investigation or diagnostic yield. When used in isolation in older children it predicted a lower rate of CT imaging and lower diagnostic yield. We would recommend that use of the simple AVPU is beneficial to initial assessment of infants with head injury but is not sensitive enough to monitor change in levels of consciousness and would, therefore, not be recommended for ongoing monitoring of clinical status in this age group.

Acknowledgements Members of the original and subsequent CMACE Head Injury External advisory group: Professor Robert Tasker, Paediatrics, University of Cambridge; Dr Rosemary Arthur, Consultant Paediatric Radiologist, Leeds (British Society Paediatric Radiology); Mr Richard Edwards MD, Department of Neurosurgery, Bristol Hospital for Children; Ms Rosie Houston Research fellow CMACE; Dr Phillip Hyde MBBS, Paediatric Intensive Care Unit, Southampton Children's Hospital; Dr lan Maconochie PhD, Imperial College NHS Healthcare Trust, London, UK, Dr Fiona Lecky, Research Director TARN, Senior Lecturer, Honorary Consultant Emergency Medicine, Manchester; Dr Fiona Moore, Medical Director London Ambulance Service; Dr Kevin Morris, Director PICU Birmingham Children's Hospital; Dr Roger Parslow PhD, Senior Lecturer in Epidemiology, Leeds Institute of Cardiovascular and Metabolic Medicine, University of Leeds; Dr Gale Pearson Consultant in Intensive Care, Birmingham Children's Hospital; Lisa Turan, Chief Executive Child Brain Injury Trust; Girkamal Virdi, Assistant Head of Clinical and Audit Research, London Ambulance Service; Mark Woolcock, Emergency Medical Practitioner and Emergency Specialist Service, South Western Ambulance Service, NHS Foundation Trust.

Contributors AN: Medical student who undertook some of the data analysis and ran a second check on the statistical analysis undertaken by KMP. AN was lead author and contributed to the manuscript and undertook a literature search. KMP: Biosciences student undertook the primary data analysis, literature search and wrote the first draft of the paper. AMK: Principal investigator on the overall analysis of the dataset, supervised the student participation in the project. Edited, checked and finalized the final draft.

Funding This project/audit was commissioned and funded by the Healthcare Quality Improvement Partnership (HQIP) Traumatic head injury in children and young people: a national overview as part of the National Clinical Audit and Patient Outcomes Programme (NCAPOP). This is one of a series of publications using the study data.
Competing interests None declared.

Patient consent Not required.

Ethics approval The project was approved by the Central Manchester Research Ethics Committee (Ref 09/H1008/74) and was registered with hospital R\&D or clinical governance departments in the participating hospitals. Approvals were renewed when the project was transferred to Cardiff University for analysis and updated in July 2012 (Ref 09/H1008/74).

Provenance and peer review Not commissioned; externally peer reviewed.

Data sharing statement Primary data-set has been destroyed subject to HQIP requirements.

Open access This is an open access article distributed in accordance with the Creative Commons Attribution Non Commercial (CC BY-NC 4.0) license, which permits others to distribute, remix, adapt, build upon this work non-commercially, and license their derivative works on different terms, provided the original work is properly cited, appropriate credit is given, any changes made indicated, and the use is non-commercial. See: http://creativecommons.org/licenses/by-nc/4.0/.

\section{REFERENCES}

1. NHS Digital. Hospital episode statistics. http://www.hscic.gov.uk/hes (Accessed Aug 2015).

2. Hawley C, Wilson J, Hickson C, et al. Epidemiology of paediatric minor head injury: comparison of injury characteristics with Indices of Multiple Deprivation. Injury 2013;44:1855-61.

3. National Institute for Health and Clinical Excellence. Head injury: triage, assessment, investigation and early management of head injury in children, young people and adults. https://www.nice.org.uk/ guidance/cg176/resources/guidance-head-injury-pdf (Accessed 29 July/ 2015).

4. Teasdale G, Jennett B. Assessment of coma and impaired consciousness. A practical scale. Lancet 1974;2:81-4.

5. Teasdale G, Jennett B. Assessment and prognosis of coma after head injury. Acta Neurochir 1976;34:45-55.

6. Teasdale G, Maas A, Lecky F, et al. The Glasgow Coma Scale at 40 years: standing the test of time. Lancet Neurol 2014;13:844-54.

7. GCS. Child's Glasgow Coma Scale. http://www.bpna.org.uk/audit/ GCS.PDF (Accessed 29 Jul 2015).

8. Middleton PM. Practical use of the Glasgow Coma Scale; a comprehensive narrative review of GCS methodology. Australas Emerg Nurs J 2012;15:170-83.

9. Baker M. Reviewing the application of the Glasgow Coma Scale: Does it have interrater reliability? British Journal of Neuroscience Nursing 2008;4:342-7.

10. Zuercher M, Ummenhofer W, Baltussen A, et al. The use of Glasgow Coma Scale in injury assessment: a critical review. Brain Inj 2009;23:371-84.

11. American College of Surgeons' Committee on Trauma. Advanced trauma life support for doctors. 1977;6.

12. Matthew $\mathrm{H}$, Lawson $\mathrm{A}$. Acute barbiturate poisoning - a review of two years experience. QJM 1966;35:539-52.

13. Mackay C, Burke D, Burke J, et al. Association between the assessment of conscious level using the AVPU system and the Glasgow coma scale. Prehospital Immediate Care 2000;4:17-19.

14. Trefan L, Houston R, Pearson G, et al. Epidemiology of children with head injury: a national overview. Arch Dis Child 2016;101:527-32.

15. VassarStats. Website for statistical computation. 2014. Available at http://vassarstats.net/prop1.html.

16. Kemp A, Nickerson E, Trefan L, et al. Selecting children for head CT following head injury. Arch Dis Child 2016;101:929-34.

17. Raman S, Sreenivas V, Puliyel JM, et al. Comparison of alert verbal painful unresponsiveness scale and the Glasgow Coma Score. Indian Pediatr 2011;48:331-2.

18. Hoffmann F, Schmalhofer M. Lehner M, et al.Z (2016) Comparison of the AVPU scale and the pediatric GCS in prehospital setting. Prehospital Emergency Care 2016;20:4:493-8

19. Prasad K. The Glasgow Coma Scale: a critical appraisal of its clinimetric properties. J Clin Epidemiol 1996;49:755-63.

20. McNarry AF, Goldhill DR. Simple bedside assessment of level of consciousness: comparison of two simple assessment scales with the Glasgow Coma scale. Anaesthesia 2004;59:34-7.

21. Kelly CA, Upex A, Bateman DN. Comparison of consciousness level assessment in the poisoned patient using the alert/verbal/painful/ unresponsive scale and the glasgow coma scale. Ann Emerg Med 2004;44:108-13. 